\title{
AVALIAÇÃO DA INFLUÊNCIA DOS MILHOS GPM NAS CARACTERÍSTICAS SENSORIAIS DE BOLO ${ }^{1}$
}

\author{
Fabrício Leal ROCHA², Valéria Paula Rodrigues MINIM², Flavia DELLA LUCIA², \\ Luis Antonio MINIM², Jane Sélia dos Reis COIMBRA²
}

\begin{abstract}
RESUMO
Atualmente já não existem mais dúvidas sobre o potencial nutricional dos milhos QPM na alimentação humana. No entanto pouco se conhece sobre os milhos QPM (Quality Protein Maize) na produção de alimentos. O presente trabalho teve como objetivo avaliar o efeito da adição de diferentes variedades de milho nas características de aparência, aroma, sabor e textura de bolo de fubá utilizando análise descritiva quantitativa. Sete formulações foram avaliadas por uma equipe de provadores treinados, onze atributos sensoriais foram definidos. Após um período de treinamento, os provadores avaliaram as amostras através de delineamento de blocos incompletos balanceados usando escala não estruturada de $9 \mathrm{~cm}$. As mesmas foram também avaliadas em relação a aceitabilidade através da escala hedônica de 9 pontos, por 70 consumidores de bolo de fubá. Os resultados foram analisados através da ANOVA seguida pelo teste de Tukey. As amostras apresentaram diferença significativa $(p<0,05)$ em todos os atributos avaliados. As formulações diferiram quanto à aceitabilidade $(p<0,05)$. Estas se situaram entre os termos hedônicos "gostei ligeiramente" e "gostei moderadamente"

Palavras-chave: milhos QPM; bolo de fubá; análise sensorial e análise descritiva quantitativa.
\end{abstract}

\section{SUMMARY}

EFFECTS OF QPM ADDITION ON THE SENSORY CHARACTERISTICS OF CAKE MAIZE. There are no doubts about the nutritional potential of the QPM maizes on the human feed. However we have a little knowledge about QPM maizes for food formulation. The present work evaluated, by quantitative descriptive analysis, the effect on the appearance, aroma, flavour and texture of maize cake when different varieties of maize were added. Seven formulations were evaluated by a selected panel and twelve attributes were defined. After a training period, the panel evaluated the samples in a incomplete block design using a $9 \mathrm{~cm}$ unstructured scale. The developed formulations were also studied in relation to acceptability through the hedonic scale of 9 points, for 70 consumers of maize cake. The results were analyzed by ANOVA and Tukey test. Samples showed significant differences $(p<0,05)$ in all sensory attributes. Significant acceptance $(p<0,05)$ was observed among the samples.

Keywords: QPM maize; maize cake; sensory evaluation and quantitative descriptive analysis.

\section{1 - INTRODUÇÃO}

O milho é um dos três cereais mais consumidos no mundo, responsável pelo fornecimento de aproximadamente $15 \%$ das proteinas de origem vegetal e $19 \%$ do total das calorias fornecidas pelos alimentos [16].

O Brasil é o terceiro maior produtor de milho do mundo, com mais de 30 milhões de toneladas sendo colhidas anualmente [1]. São cerca de 22,5 milhões de toneladas de amido, 2,6 milhões de toneladas de proteínas e 1,2 milhões de toneladas de óleo fornecidos por esse cereal [5]. Tais valores representam um valor energético e protéico inestimável, especialmente em dietas onde predominam as associações cereais/leguminosas.

Entretanto, a proteina do milho é deficiente em lisina e triptofano e apresenta excesso de leucina [26]. Este é um problema que se tentou resolver por meio de suplementação com aminoácidos sintéticos, mas os altos custos dos produtos enriquecidos tornaram inviável esta solução [21].

Em 1963, pesquisadores da Universidade de Purdue, nos Estados Unidos, descobriram um gene mutante de milho (então denominado "Opaco 2") com pelo menos duas vezes mais lisina que o milho normal e alto teor de

1. Recebido para publicação em 02/05/2001. Aceito para publicação em 26/12/2002 (000633).

2. Departamento de Tecnologia de Alimentos - Universidade Federal de Viçosa-Viçosa-MG, CEP 36571-000.

* A quem a correspondência deve ser enviada. triptofano. Entretanto, associadas a este gene, estavam algumas características indesejáveis, como baixa densidade do grão, fazendo com que a versão opaca fosse sempre um pouco menos produtiva que a normal; alta suscetibilidade a pragas e doenças, tanto no campo quanto armazenado; tempo de secagem mais longo que o do milho comum; aparência opaca do grão, diferente do aspecto vitreo com o qual os produtores estavam acostumados. Devido a esses fatores, o cultivo de milho opaco foi praticamente abandonado em meados da década de setenta [14].

No decorrer da última década, no México, foi feito um trabalho longo e continuo envolvendo pesquisaores do Centro Internacional de Melhoramento de Milho e Trigo (CIMMYT), visando aumentar a freqüência de genes modificadores em compostos de ampla base genética, portadores do gene "Opaco 2". Após seis a sete ciclos de seleção recorrente, foi possivel obterem-se variedades estáveis com endosperma vítreo e altos teores de lisina e triptofano na proteina do endosperma. Estes progressos na seleção foram acompanhados de melhoria na produtividade, resistência a doenças e pragas e aumento na densidade dos grãos. O novo tipo de milho que combina o excelente valor nutricional do "Opaco 2" com todas as características agronômicas desejáveis do milho passou a ser chamado de "QUALITY PROTEIN MAIZE (QPM)" [17].

No Brasil, em 1952, pequisadores da Universidade Estadual de Campinas compararam a composição quimica e valor nutritivo de um cultivar de milho, duplo mutante denominada Nutrimaiz em relação aos ascedentes (Doce 
Piramex, Maya Normal e Maya Opaco-2). Os autores concluíram que a Nutrimaiz se caracterizou por possuir as preteinas com características químicas e nutritivas semelhantes ao Opaco-2 [20]. Além disto, Nutrimaiz apresentou excelente comportamento agronômico e uma maturação mais lenta, permitindo a sua utilização como milho verde por um periodo de 3-4 semanas, superior a qualquer uma das três cultivares utilizadas [22].

Vários estudos foram realizados a respeito do potencial nutricional dos milhos QPM [3, 7, 8, 9, 10, 11, 12, 25, 27]. Entretanto, até o momento nenhuma pesquisa foi realizada avaliando a influência dos milhos QPM nas características sensoriais de produtos alimenticios.

O presente trabalho teve como objetivo avaliar o efeito da adição de diferentes variedades de milho nas características sensoriais e na aceitabilidade do bolo de fubá.

\section{2 - MATERIAL E MÉTODOS}

\section{1 - Formulações}

Foram utilizados para a fabricação dos bolos, fubá integral peneirado proveniente do milho comum (BR 201), amarelo QPM (BR473) e branco QPM (BR451), todos provenientes do Centro Nacional de Pesquisa de Milho e Sorgo (CNPMS / EMBRAPA).

Os outros ingredientes foram adquiridos no comércio local de Viçosa-MG, observando-se a adequação de apresentação e o prazo de validade. A fim de ter uma padronização das formulações utiliza-se sempre dos mesmos fornecedores.

Foi desenvolvida uma formulação padrão para todas as amostras; sendo a avariação do tipo de fubá e a proporção deste em relação a farinha total as únicas variações entre as mesmas (Tabela 1)

O preparo das formulações foi realizado seguindo as etapas de:

- Mistura do açúcar junto a margarina em batedeira planetária ARNO, por 10 minutos;

- Adição de farinha de trigo juntamente com o fubá;

- Adição do leite e ovos;

- A massa foi batida em velocidade média por 4 minutos;

- O fermento químico foi adicionado por último sem o uso da batedeira para misturá-1o;

- A massa foi despejada em formas retangulares previamente untadas com margarina e farinha de trigo e assada em forno convencional por 40 minutos a $180^{\circ} \mathrm{C}$;

- Depois de esfriado por 15 minutos o bolo foi desenformado;

\subsection{Análise sensorial}

\subsubsection{Recrutamento e pré-seleção de provadores}

Voluntários para compor a equipe sensorial foram recrutados dentre os estudantes e funcionários do De- partamento de Tecnologia de Alimentos da UFV. Aplicou-se um questionário para avaliar disponibilidade de tempo, saúde, interesse, capacidade de utilizar termos descritivos e de utilizar escalas. Desta forma, dezenove homens e dezesseis mulheres na faixa de 20 a 30 anos foram recrutados. Em seguida, a habilidade de cada indivíduo em discriminar diferença sensorial em bolo de fubá, foi julgada, aplicando-se para cada indivíduo, uma série de testes triangulares e selecionando-se os provadores que acertaram no mínimo 50\% dos testes, conforme MEILGARD et al. [13].

\subsubsection{Seleção de formulações para análise des- critiva}

Com o objetivo de selecionar para os testes descritivos, apenas formulações que apresentassem diferença sensorial entre si a $\mathrm{p} \leq 0,05$ utilizou-se o teste de diferença do controle. Assim, os provadores pré-selecionados determinaram em cada grupo de três formulações, as que diferiam de uma amostra controle previamente especificada. Cada grupo foi formado utilizando-se fubá proveniente de um mesmo milho. Nos três grupos a formulação com 33,3\% de fubá em relação a farinha total foi considerada a padrão.

TABELA 1. Composição das formulações avaliadas.

\begin{tabular}{|c|c|c|c|c|c|c|c|c|c|}
\hline \multirow[t]{2}{*}{ INGREDIENTES } & \multicolumn{9}{|c|}{ FORMULAÇÕES* } \\
\hline & B33 & B50 & B66 & $\mathbf{A 3 3}$ & A50 & A66 & $\mathrm{C} 33$ & C50 & C66 \\
\hline Farinha de trigo(g) & 133,3 & 100 & 66,6 & 133,3 & 100 & 66,6 & 133,3 & 100 & 66,6 \\
\hline Fubá(g) & 66,6 & 100 & 133,3 & 66,6 & 100 & 133,3 & 66,6 & 100 & 133,3 \\
\hline Margarina(g) & 125 & 125 & 125 & 125 & 125 & 125 & 125 & 125 & 125 \\
\hline Ovos(g) & 120 & 120 & 120 & 120 & 120 & 120 & 120 & 120 & 120 \\
\hline Açúcar refinado(g) & 100 & 100 & 100 & 100 & 100 & 100 & 100 & 100 & 100 \\
\hline Fermento químico & 8,5 & 8,5 & 8,5 & 8,5 & 8,5 & 8,5 & 8,5 & 8,5 & 8,5 \\
\hline Leite integral(mL) & 100 & 100 & 100 & 100 & 100 & 100 & 100 & 100 & 100 \\
\hline
\end{tabular}

Em cada sessão de teste os provadores receberam uma formulação padrão, especificada com a letra $\mathrm{P}$, e três formulações codificadas. Dentre as formulações codificadas, uma era igual a padrão e as outras duas tinham proporções de $50 \%$ e 66,6\% de fubá em relação a farinha total dentro de cada grupo de milho. Era pedido aos provadores para comparar as formulações com a padrão e avaliar a existência de diferença entre a formulações codificada e a padrão.

Os resultados do teste de diferença do controle foram avaliados através da Análise de Variância (ANOVA) e teste de média Dunnett, comparando-se apenas a padrão com as demais formulações. 


\subsection{3 - Análise descritiva quantitativa}

O método empregado é uma adaptação da Análise Descritiva Quantitativa desenvolvida por STONE et al. [23], que permite descrever as principais caracteristicas que compõem a aparência, aroma, textura e sabor de um alimento, além de medir a intensidade das sensações percebidas [24].

\section{- Condições do teste}

Os testes sensoriais foram realizados no laboratório de Análise Sensorial do Departamento de Tecnologia de Alimentos da Universidade Federal de Viçosa, em cabines individuais com utilização de iluminação vermelha, bandejas plásticas e pratos de porcelana de fundo preto, para avaliar aroma, sabor e textura. Este procedimento é utilizado para mascarar diferenças na aparência que possam influenciar o provador. A aparência foi avaliada fora da cabine, com iluminação natural. Um copo de $100 \mathrm{~mL}$ de água filtrada a temperatura ambiente foi utilizado pelo provador para enxaguar a boca entre as avaliações.

- Levantamento de terminologia descritiva e treinamento dos provadores

A geração dos descritores foi realizada através do método rede [15]. As sete formulações foram apresentadas aos pares, em todas as combinações possiveis, aos provadores. Estes descreveram as similaridades e diferenças entre cada par de formulações com relação a aparência, aroma, sabor e textura.

Após as avaliações em cabines individuais, os provadores foram reunidos e foi providenciada a definição dos termos descritivos pela equipe. Em seguida, de posse de uma ampla lista de termos levantados, sob a supervisão do líder de equipe, os provadores discutiram o significado de cada termo, eliminaram termos correlatos, agruparam termos sinônimos. Materiais de referência foram providenciados para cada termo descritivo levantado visando o treinamento dos provadores e a padronização na utilização de cada termo. Assim, após a realização de várias sessões foram obtidas a lista de referências, a definição de cada termo descritivo e a ficha de avaliação.

A ficha de avaliação das formulações continha uma escala não estruturada para cada termo descritivo levantado. A escalas eram de $9 \mathrm{~cm}$, tendo expressões quantitativas (pontos-âncora) nas extremidades esquerda e direita com os termos claro/escuro, pouco/muito e fina/grosseira, respectivamente. Os provadores através de um traço vertical na escala, escolhiam a melhor posição que refletisse a sua avaliação para cada termo descritivo. Os valores foram obtidos medindo-se a distância entre o ponto-âncora da extremidade esquerda e o traço vertical feito pelo provador, com o auxilio de uma régua.

\section{- Seleção de provadores}

Após o treinamento, com o objetivo de verificar o desempenho dos provadores, foi feito um teste preliminar avaliando duas formulações, com três repetições, utilizando os termos descritivos levantados no treina- mento. As avaliações realizadas obedeceram ao delineamento de blocos completamente casualizados.

Os resultados individuais de cada provador, para cada atributo, foram estatisticamente avaliados por Análise de Variância (ANOVA), tendo como causas de variação: amostras e repetições. Os niveis de significância (p) dos valores de $\mathrm{F}$ (amostras) e F (repetições) foram computados para cada provador, em cada atributo. Dez provadores foram finalmente selecionados com base em sua capacidade discriminatória $\left(\mathrm{pF}_{\text {amostras }}<0,50\right)$, reprodutibilidade $\left(\mathrm{pF}_{\text {repeticōes }}\right.$ $>0,05$ ) e julgamento consensual com o restante da equipe de provadores, conforme sugerido pela ASTM [1] e DAMÁSIO \& COSTELL [6].

- Avaliação das formulações e análise dos resultados

Utilizando-se os atributos levantados, 10 provadores selecionados e treinados avaliaram as formulações.

Optou-se pelo delineamento de blocos incompletos balanceados para sete formulações [4], com os seguintes parâmetros:

$\mathrm{t}=$ número total de formulações a serem analisadas $=7$

$\mathrm{k}=$ número de unidades por bloco $=3$

$\mathrm{r}=$ número de repetições $=3$

$\mathrm{b}=$ número de blocos $=7$

Foi realizada análise de variância com interação para avaliação das formulações. A significância estatística das diferenças entre as médias foi determinada mediante o teste de Tukey.

Todas as análises estatísticas foram realizadas em microcomputador utilizando programas do pacote estatístico SAS [19].

\subsection{4 - Teste de aceitação}

A avaliação aceitabilidade sensorial das sete formulações de bolo de fubá foi realizada no laboratório de Análise Sensorial do Departamento de Tecnologia de Alimentos da Universidade Federal de Viçosa.

As sete formulações foram apresentadas aos consumidores através do delineamento de blocos incompletos balanceados ( $t=7, k=3, r=3$ e $b=7$ ) e setenta consumidores de bolo de fubá realizaram os testes. Desta forma, cada formulação foi avaliada por 30 consumidores. Os provadores avaliaram a aceitação global das formulações utilizando escala hedônica de 9 pontos, em que o ponto 9 correspondia ao "gostei extremamente", o ponto 5 "indiferente" e o ponto 1 ao termo hedônico "desgostei extremamente". O modelo da escala hedônica esta apresentada na Figura 1.

\section{3 - RESULTADOS E DISCUSSÕES}

De 25 provadores recrutados apenas 14 foram selecionados para participar do processo de desenvolvimento de terminologia descritiva.

$\mathrm{Na}$ seleção de formulações para o teste descritivo, após o teste de diferença do controle e da análise de 
variância dos resultados obtidos, observou-se que existe diferença significativa $(\mathrm{p}<0,05)$ entre as formulações e concluiu-se que no grupo formado pelas formulações com fubá de milho comum (BR201), a formulação C50 não diferiu da padrão C33 e a C66 diferiu da padrão, ao nivel de $5 \%$ de significância. No grupo formado pelas formulações com fubá de milho branco QPM (BR451) as formulações B50 e B66 diferiram da padrão B33 $(p<0,05)$. No grupo das formulações com fubá de milho amarelo QPM (BR473), a formulação A50 não diferiu da padrão ( $p>0,05)$ e a $A 66$ diferiu da padrão $(\mathrm{p}<0,05)$.

Nome: Data:

Por favor, avalie as amostras, utilizando a escala abaixo para descrever o quanto você gostou ou desgostou dos bolos de fubá. Marque a posição da escala que melhor reflita seu julgamento.

\begin{tabular}{|c|c|c|}
\hline Amostra $\mathrm{N}^{\circ}$.............. & Amostra $\mathrm{N}^{\circ} . . . \ldots \ldots \ldots . . . .$. & $\mathrm{N}^{\circ} \ldots \ldots \ldots \ldots$ \\
\hline ()Gostei extremamente & ( )Gostei extremamente & ()Gostei extremamente \\
\hline ()Gostei muito & ()Gostei muito & ()Gostei muito \\
\hline ( )Gostei moderadamente & ()Gostei moderadamente & ()Gostei moderadamente \\
\hline ( )Gostei ligeiramente & ()Gostei ligeiramente & ()Gostei ligeiramente \\
\hline ( )Indiferente & ( )Indiferente & ()Indiferente \\
\hline ( )Desgostei ligeiramente & ( )Desgostei ligeiramente & () Desgostei ligeiramente \\
\hline ( )Desgostei moderadamente & ( )Desgostei moderadament & ()Desgostei moderadamente \\
\hline ( )Desgostei muito & ( )Desgostei muito & ( )Desgostei muito \\
\hline ( )Desgostei extremamente & ()Desgostei extremamente & () Desgostei extremamente \\
\hline
\end{tabular}

FIGURA 1. Modelo de ficha de resposta para teste de aceitação - escala hedônica.

Com base nos resultados obtidos, as formulações A50 e C50 foram excluídas e conseqüentemente o número de formulações a serem analisadas pelo método descritivo foi reduzido para sete (B33, B50, B66, A33, A66, C33 e C66).

Após ter sido levantada uma ampla lista de termos descritivos chegou-se pelo consenso entre os provadores, a onze termos que melhor caracterizavam as formulações de bolo de fubá. As definições e referências dos termos descritivos estão apresentadas na Tabela 2.

Os resultados da Análise de Variância demonstraram que existe diferença significativa entre as amostras em todos os atributos ao nivel de 0,5\% de probabilidade.

Quanto aos provadores, houve diferença significativa $(\mathrm{p}<0,05)$ para todos os atributos analisados. Esta diferença está provavelmente relacionada, segundo STONE et al. [23] e POWERS, CENCIARELLI, SCHINHOLSER [18], ao fato de que os provadores ao analisarem as amostras utilizaram partes diferentes da escala.

Avaliando-se a fonte de variação interação amostra versus provador verificou-se efeito significativo $(p<0,05)$ para todos os atributos.
O teste de efeito de amostras foi realizado novamente utilizando-se o quadrado médio da interação amostra versus provador como resíduo no cálculo do valor de $\mathrm{F}$, conforme recomendado por STONE e SIDEL [24]. Verificou-se então diferenças significativas para todos os atributos levantados.

Os resultados do teste de comparação de médias estão apresentados na Tabela 3. O bolo formulado com $66,6 \%$ de fubá proveniente de milho comum (C66) apresentou a maior intensidade de cor amarela, diferindo $(p<0,05)$ das demais formulações. Os três bolos (B33, B50 e B66) formulados com fubá proveniente de milho branco QPM (BR451) apresentaram menor intensidade de cor.

TABELA 2. Definições e referências dos atributos sensoriais para bolo de fubá.

\begin{tabular}{ll}
\multicolumn{1}{c}{ ATRIBUTOS } & \multicolumn{1}{c}{ DEFINIÇÕES E REFERÊNCIAS } \\
\hline COR AMARELA & $\begin{array}{l}\text { Cor característica do miolo do bolo. } \\
\text { Referência: Para o amarelo claro foi formulado um bolo usando } \\
\text { 100\% de farinha de trigo. Para o amarelo escuro bolo com 80\% } \\
\text { de fubá de milho comum (BR 201) em relação a farinha total }\end{array}$ \\
\hline BRILHO & $\begin{array}{l}\text { Qualidade de reflexão da luz. } \\
\text { Referência: para pouco brilho, bolo com 33,3\% de fubá branco } \\
\text { (QPM 451) em relação a farinha total e para muito brilho, bolo } \\
\text { com 66,6\% de fubá comum (BR 201) em relação a farinha total. }\end{array}$ \\
\hline ESTRUTURA & $\begin{array}{l}\text { Atributo de aparência em relação a estrutura do centro do bolo. } \\
\text { Referência: Para uma estrutura fina utilizou-se bolo com 50\% de } \\
\text { fubá branco (QPM 451) e para uma estrutura grosseira com 80\% } \\
\text { de fubá comum (BR 201) em relação a farinha total. }\end{array}$ \\
\hline AROMA E SABOR & $\begin{array}{l}\text { Aroma e sabor de bolo preparado com fubá de milho Referência: } \\
\text { Para aroma e sabor muito característico de bolo de fubá, bolo } \\
\text { DE BOLO DE FUBÁ } \\
\text { com 80\% de fubá comum (BR 201) e para aroma e sabor pouco } \\
\text { característico, bolo preparado com 100\% de farinha de trigo em } \\
\text { relação a farinha total. }\end{array}$ \\
\hline AROMA DE & $\begin{array}{l}\text { Aroma associado a presença de margarina na formulação do } \\
\text { bolo de fubá. }\end{array}$ \\
MARGARINA & $\begin{array}{l}\text { Referência: Para o aroma muito intenso, bolo com 175g de margarina } \\
\text { e para um aroma pouco intenso, bolo com 75g de margarina. }\end{array}$ \\
\hline SABOR RESIDUAL & $\begin{array}{l}\text { Sensação olfatogustativa que ocorre após a degustação do bolo } \\
\text { devido a presença da margarina na formulação. }\end{array}$ \\
\hline Referência: As mesmas referências para o aroma de margarina.
\end{tabular}

Em relação ao atributo brilho também verificou-se que a formulação $\mathrm{C66}$ apresentou este atributo em maior intensidade e as formulações B33, B50 e B66 apresentaram este atributo em menor intensidade.

A formulação C66 apresentou o bolo com a estrutura mais grosseira e os bolos B33, B50 e B66 as com estrutura mais fina não diferindo entre si $(p>0,05)$.

Pela análise dos resultados em relação ao aroma característico, observa-se que o bolo C66 apresentou maior intensidade e que os bolos B33, B50 e B66 são os de menor intensidade. 
TABELA 3. Médias das características sensoriais das formulações de bolo de fubá.

\begin{tabular}{|c|c|c|c|c|c|c|c|}
\hline \multirow[t]{2}{*}{ ATRIBUTOS } & \multicolumn{7}{|c|}{ FORMULAÇÕES } \\
\hline & B33 & B50 & B66 & $\mathbf{A 3 3}$ & A66 & C33 & C66 \\
\hline Cor amarela & $1,1 \mathrm{f}$ & $1,8 \mathrm{e}$ & $1,5 \mathrm{e}, \mathrm{f}$ & $5,2 \mathrm{c}$ & $7,1 \mathrm{~b}$ & $4,4 \mathrm{~d}$ & $8,0 \mathrm{a}$ \\
\hline Brilho & $2,3 \mathrm{c}$ & $3,2 \mathrm{c}$ & $3,1 \mathrm{c}$ & $4,5 \mathrm{~b}$ & $5,0 \mathrm{~b}$ & $4,1 \mathrm{~b}$ & $6,9 \mathrm{a}$ \\
\hline Estrutura & $2,0 \mathrm{~d}$ & $2,0 \mathrm{~d}$ & $1,9 \mathrm{~d}$ & $3,7 \mathrm{c}$ & $3,8 \mathrm{c}$ & $6,3 \mathrm{~b}$ & $7,4 \mathrm{a}$ \\
\hline $\begin{array}{c}\text { Aroma } \\
\text { característico }\end{array}$ & $2,2 \mathrm{e}$ & $3,5 \mathrm{~d}$ & $3,2 \mathrm{~d}, \mathrm{e}$ & $4,8 \mathrm{c}$ & $6,4 \mathrm{~b}$ & $5,3 \mathrm{c}$ & $7,6 \mathrm{a}$ \\
\hline $\begin{array}{l}\text { Aroma de } \\
\text { Margarina }\end{array}$ & $2,0 \mathrm{c}$ & $3,1 \mathrm{c}$ & $4,6 \mathrm{~b}$ & $5,0 \mathrm{~b}$ & $4,3 \mathrm{~b}$ & $5,4 \mathrm{a}, \mathrm{b}$ & $6,4 \mathrm{a}$ \\
\hline Gosto doce & $3,7 \mathrm{c}$ & $4,4 a, b, c$ & $5,3 \mathrm{a}$ & $5,3 \mathrm{a}$ & $4,8 \mathrm{a}, \mathrm{b}$ & 4,6a,b,c & $4,3 \mathrm{~b}, \mathrm{c}$ \\
\hline $\begin{array}{l}\text { Sabor residual } \\
\text { Margarina }\end{array}$ & $2,2 \mathrm{~d}$ & $2,7 \mathrm{c}, \mathrm{d}$ & $5,0 \mathrm{a}, \mathrm{b}$ & $4,4 \mathrm{~b}$ & $3,8 \mathrm{~b}, \mathrm{c}$ & $4,7 \mathrm{~b}$ & $6,3 \mathrm{a}$ \\
\hline $\begin{array}{c}\text { Sabor } \\
\text { característico }\end{array}$ & $2,2 \mathrm{e}$ & $3,5 \mathrm{~d}$ & $3,2 \mathrm{~d}, \mathrm{e}$ & $4,8 \mathrm{c}$ & $6,4 \mathrm{~b}$ & $5,3 \mathrm{c}$ & $7,6 \mathrm{a}$ \\
\hline Maciez & $6,7 \mathrm{a}$ & $4,7 \mathrm{~b}$ & $4,0 \mathrm{~b}, \mathrm{c}$ & $6,0 \mathrm{a}$ & $3,5 \mathrm{c}$ & $6,4 \mathrm{a}$ & $1,8 \mathrm{~d}$ \\
\hline Granulosidade & $1,2 \mathrm{e}$ & $1,9 \mathrm{~d}, \mathrm{e}$ & $2,6 \mathrm{~d}$ & $2,7 \mathrm{~d}$ & $4,3 \mathrm{c}$ & $5,6 \mathrm{~b}$ & $7,6 \mathrm{a}$ \\
\hline Fraturabilidade & $2,8 \mathrm{~d}$ & $4,0 \mathrm{~b}, \mathrm{c}, \mathrm{d}$ & $4,2 \mathrm{~b}, \mathrm{c}$ & $3,3 \mathrm{c}, \mathrm{d}$ & $4,9 \mathrm{~b}$ & $3,4 \mathrm{c}, \mathrm{d}$ & $7,1 \mathrm{a}$ \\
\hline $\begin{array}{l}\text { B33 }=\text { Formulaç } \\
\text { B50 = Formulaç } \\
\text { B66 = Formulaç } \\
\text { A33 = Formulaç } \\
\text { A66 = Formulaç } \\
\text { C33 = Formulaç } \\
\text { C66 = Formulaç } \\
\left({ }^{*}\right) \text { As médias seg } \\
\text { de probalidade. }\end{array}$ & $\begin{array}{l}\text { con } \\
\text { con } \\
\text { con } \\
\text { con } \\
\text { idas }\end{array}$ & $\begin{array}{l}\text { ndo } 33,3 \\
\text { ndo } 50 \% \\
\text { ndo } 66,6 \\
\text { ndo } 33,3 \\
\text { ndo } 66,6 \\
\text { ndo } 33,3 \\
\text { ndo } 66,6 \\
\text { la mesm }\end{array}$ & $\begin{array}{l}\text { de fu } \\
\text { de fu } \\
\text { de fu } \\
\% \text { de } \\
\text { letra } n\end{array}$ & $\begin{array}{l}\text { marel } \\
\text { marel } \\
\text { omum } \\
\text { comu } \\
\text { esma } 1\end{array}$ & $\begin{array}{l}\text { M (BR4 } \\
\text { (BR45 } \\
\text { M (BR4 } \\
\text { MM (BR } \\
\text { MM (BR } \\
2201 \text { ) } \\
\text { 3R201) } \\
\text { a não d }\end{array}$ & 3) & si a $5 \%$ \\
\hline
\end{tabular}

TABELA 4. Comparação das médias obtidas no teste de aceitação das diferentes formulações de bolo de fubá.

$\begin{array}{cc}\text { Formulações } & \text { Escores Médios de Aceitação } \\ \text { A66 } & 7,6 \mathrm{a} \\ \text { A33 } & 7,4 \mathrm{ab} \\ \text { B33 } & 7,3 \mathrm{ab} \\ \text { B50 } & 7,1 \mathrm{ab} \\ \text { B66 } & 7,1 \mathrm{ab} \\ \text { C33 } & 6,9 \mathrm{ab} \\ \text { C66 } & 6,6 \mathrm{~b}\end{array}$

As médias seguidas de pelo menos uma mesma letra não diferiram entre si pelo Teste Tukey, ao nivel de $5 \%$ de probabilidade $(\mathrm{p}>0,05)$

Quanto ao sabor residual de margarina, aroma de margarina e granulosidade, o bolo $\mathrm{C} 66$ apresentou maior intensidade e os bolos B33 e B50 menor intensidade nos três atributos.

O bolo C66 apresentou o atributo sabor característico em maior intensidade diferindo das demais formulações $(\mathrm{p}<0,05)$ e os bolos (B33, B50 e B66) formulados com fubá proveniente do milho branco QPM em menor intensidade.

Com relação a maciez, os bolos B33, C33 e A33 apresentaram maior intensidade diferindo das demais formulações e o bolo C66 foi o que apresentou menor maciez. Os resultados demonstraram que aumentando a concentração de fubá nos três diferentes tipos de milho estudados diminuiu a maciez do bolo.
Em relação a fraturabilidade o bolo C66 apresentou maior intensidade diferindo das demais amostras ao nivel de $5 \%$ de probabilidade.

Os resultados do teste de aceitação demonstraram que o bolo A66, formulado com $66,6 \%$ de fubá amarelo QPM (BR453), obteve melhor aceitação diferindo significativamente $(p<0,05)$ do C66, formulado com $66,6 \%$ de fubá comum (BR201). O bolo A66 situou-se entre os termos hedônicos "gostei muito" e "gostei moderadamente" e o C66 entre "gostei moderadamente" e gostei ligeiramente". As demais amostras não diferiram entre si em relação a aceitação $(p>0,05)$ e situaram-se entre os "termos gostei muito" e "gostei ligeiramente" (Tabela 4).

\section{4 - CONCLUSÕES}

- Através do método rede e do consenso entre a equipe treinada de provadores chegou-se a uma lista de 11 atributos que melhor caracterizaram o perfil sensorial do bolo de fubá formulado com milho comum (BR421), milho amarelo QPM (BR 453) ou milho branco QPM (BR 451).

- Existiu diferença significativa entre as amostras em todos os termos descritivos ao nivel de $5 \%$ de probabilidade.

- O bolo formulado com $66,6 \%$ de fubá de milho amarelo QPM (BR473) obteve melhor aceitação que o formulado com $66,6 \%$ de fubá de milho comum (BR201). Portanto, a substituição de milho comum pelo amarelo QPM além de melhorar as qualidades nutricionais, aumentou a aceitabilidade do bolo.

\section{5 - REFERÊNCIAS}

[1] ABImilho. Disponível em: http://abimilho.com.br/ estatísticas.htm. Acesso em setembro de 2002.

[2] AMERICAN SOCIETY FOR TESTING AND MATERIALS. 1976. Sensory Evaluation of Materials and Products, (STP434). ASTM, New York. 77p.

[3] BURGOON, K.G.; HANSEN, J.A.; KNABE, D.A. BOCKHOLT, A.J. Nutritional value of quality protein maize for sarter and finisher swine. Journal of Animal Science, v.70, n.3, p.811-817, 1992.

[4] COCHRAN, W.G. e COX, G.M. Experimental Resign. 2a ed. New York, Wiley Inc., p:470-476, 1957.

[5] D'ALLAGUA, L. J. Tendências da Indústria Alimentícia Brasileira em Relação aos Produtos de Milho e Sorgo para a Alimentação Humana. XX Congresso Nacional de Milho e Sorgo. Goiânia, 1994.

[6] DAMÁSIO, M.H., COSTELL, E. Analisis Sensorial Descriptivo: Generación de Descriptores y Seleción de Catadores. Rev. Agroquím. Technol. Alimentos, v. 31, n. 2, p.165178, 1991.

[7] FUCHS, G. Quality protein maize as a weaning food. Journal of Pediatric Gastroenterology and Nutrition, v. 18, n.3, p 406-407, 1994.

[8] GAZIOlA, S.A.; Alessi, E.S.; GUIMARAes, P.E.; DAMERVAL, C.; AZEVEDO,R.A. Quality protein maize: a biochemical study of enzymes involved in lisine metabolism. Journal of Agricultural and Food Chemestry, v. 47, n.3, p.1268-1275. 1999.

[9] GRAHAM, G.G. Quality protein maize with a high fat content 
as a weaning food. Journal of Pediatric Gastoenterology and Nutrition, v. 17, n.2, p. 139-144. 1993.

[10] GRAHAM, G.G. LEMBCKE, J. LANCHO, E. MORALES, E. Quality protein maize: digestibity and utilization by recorvering malnourished infants. Pediatrics, v.83, n. 3 p.416-421, 1989.

[11] GRAHAM, G.G. LEMBCKE, J.; MORALES, E. Quality protein maize: as the sole source of dietary protein and fat for rapidly growing young children. Pediatrics, v.85, n.1 p.85-91, 1990.

[12] LOPES, M.A. TAKASAKI, K.; BOSTWICK, D.E.; HELENJATJARIS, T.; LARKINS, B.A. Identification of two opaque2 modifier loci in quality protein maize. Molecular \& General Genetics, v.247, n.5, p. 603-613. 1995.

[13] MEILGARD, M. CIVILle, V \& CARR, B.T. Sensory Evaluation Techniques. CRC Press Inc. Boca Raton, Florida. 1988. 279 p.

[14] MERTZ, E.T., BATES, L.S., e NELSON, O.E. Mutant gene that changes protein composition and increases lysine content of endosperm. Science 145, 279, 1964.

[15] MOSKOWITZ, H.R. Product Testing and Sensory Evaluation of Foods. Marketing and R\&D Aproaches. Food and Nutricion Press, Inc., Westort, Conn. 1983. 605p.

[16] NATIONAL RESEARCH COUNCIL (NRC). Quality Protein Maize. Washington, National Academic Press. 1988. 105p.

[17] PEIXOTO, M. J. V. V.; PARENTONI, S. N.; GAMA, E. E. G.; MAGNAVACA, R.; PAIVA, E.; REGO, M. M. Perspectivas de utilização de milhos de alta qualidade protéica no Brasil. Inf. Agropec. 14: 23-24, 1990.

[18] POWERS, J. J.; CENCIARELLI, S.; SCHINHOLSER, E. El uso de programas estatisticos generales en la evaluacion de los resultados sensoriales. Revista Agroquímica y Tecnología de Alimentos, v.24, n.4, p. 469, 1984.

[19] SAS INSTITUTE INC. SAS USER'S GUIDE: STATISTICS, VERSION 5 EDITION. Cary NC: SAS Institute.; 1985. 965p

[20] SGARBIERI, V.C.; CONTRERAS, E; AMAYA, F.J.; SILVA, W.J.; REYES, F. Composição e valor nutritivo de quatro cultivares de milho (Zeamays) em dois estágios de maturação. Ciênc. Tecnol. Aliment., v. 2, n. 2, p. 180193, 1982.
[21] SGARBIERI, W. Alimentação e Nutrição - Fator de Saúde e Desenvolvimento. Campinas, S. P., Editora da UNICAMP, 1987. 387 p.

[22] SILVA, W. J.; TEIXEIRA J. P. F.; ARRUDA, P.; LOVATO, M. B. Nutrimaiz, a tropical sweet maize cultivar of high nutricional value. Maydica, v. 23, p. 129-136, 1978.

[23] STONE, H. SIDEL, J. L.; OLIVER, S. WOOLSEY, A.; SINON, R.C. Sensory Evaluation by Quantitative Descriptive Analysis. Food Technology v.28, n.11, p. 24-34, 1974.

[24] STONE, H; SIDEL, J.L. Sensory Evaluation Practices Academic Press, London 1985.

[25] SULLIVAN, J.S.; KNABE, D.A.; BOCKNOLT, A.J.; GREEGG, E.J. Nutritional value of quality protein maize and fool corn for starter and growth pigs. Journal of Animal Science, v.67, n.5, p.1285-1292, 1989.

[26] WOLF, W. J. \& COWAN, J. C. Soybean as a Food CRC Press, Ohio, 1975. $101 \mathrm{p}$.

[27] ZARKADAS, C.G.; HAMILTON R.I.; YU,Z. R.; CHOI, V.K.; KHANIZADETH, S.; ROSE, N.G.; PATTISON, P.L. Assessment of the protein quality of 15 new northerm adapted cultivars of quality protein maize using amino acids analysis. Journal of Agricultural and Food Chemistry, v.48, n.11, p. 5351-5361. 2000.

\section{6 - AGRADECIMENTOS}

À FAPEMIG pelo auxílio financeiro. 